\title{
An Empirical Research on Marketing Strategies of Different Risk Preference Merchant
}

\author{
Quan Chen, ${ }^{1}$ Jiangtao Wang $\mathbb{D}^{1},{ }^{1}$ Jianjun Yu $\mathbb{D}^{2},{ }^{2}$ and Sang-Bing Tsai $\mathbb{D}{ }^{1,3,4,5}$ \\ ${ }^{1}$ Zhongshan Institute, University of Electronic Science and Technology of China, Guangdong 528400, China \\ ${ }^{2}$ School of Business Administration, South China University of Technology, Guangzhou 510641, China \\ ${ }^{3}$ China Academy of Corporate Governance, Nankai University, Tianjin 300071, China \\ ${ }^{4}$ Economics and Management College, Civil Aviation University of China, Tianjin 300300, China \\ ${ }^{5}$ Business and Law School, Foshan University, Guangdong 528000, China
}

Correspondence should be addressed to Jiangtao Wang; jiangtao-w@foxmail.com, Jianjun Yu; yujj@scut.edu.cn, and Sang-Bing Tsai; sangbing@hotmail.com

Received 20 June 2017; Accepted 11 March 2018; Published 24 April 2018

Academic Editor: Leonilde Varela

Copyright (C) 2018 Quan Chen et al. This is an open access article distributed under the Creative Commons Attribution License, which permits unrestricted use, distribution, and reproduction in any medium, provided the original work is properly cited.

Holiday merchandise has unique demand characteristics, unofficial start data, and a limited life cycle. In an intensely competitive market, individual merchants are able to get more sales opportunities if they display their products earlier. In this study, a timevariant variance and time-variant expected market demand model are introduced to investigate the order strategies that are used by risk-averse holiday merchants. Our results show that risk preference, market uncertainty, and market power have a significant effect on the merchant's market strategies. Risk-averse merchants prefer to enhance forecast accuracy rather than using an early-display advantage. They can even give up their early-display advantage if they are faced with increased market uncertainty and small market power. Compared with the fixed purchase cost, the time-sensitive purchase cost can stimulate the merchant to purchase in advance, but this can decrease the merchant's profit. Consequently, risk-averse merchants always display their merchandise later, decrease the order quantity, and, finally, miss the market opportunity.

\section{Introduction}

As a special type of seasonal goods, holiday merchandise has unique demand characteristics, such as an unofficial start date and a finite selling horizon [1]. Most holiday goods are introduced into the retail market over a well-defined and finite selling horizon. They are then removed from display after the special date has passed. For example, as described by Robert Rand, "Although the holiday shopping season does not 'officially' begin until the Friday after Thanksgiving, artificial trees and holiday wreaths now appears in some store as early as September" [2]. Similarly, the Chinese Spring Festival shopping season always officially begins on 23 December. However, the New Year's gatepost couplet has recently appeared in the Chinese retail market at the beginning of December. The total amount of money that shoppers spend on holiday merchandise is largely independent of the length of the holiday. In addition, an early display entails opportunity costs. Why then do these merchants put this holiday merchandise on display so early? Frank [2] argued that the rationale behind early display is that, in a fiercely competitive market, any merchants who wait until the Friday after Thanksgiving to display Christmas wreaths will lose out to merchants who display them earlier, allowing them to capture more of the market demand (the early part) and reap the first-mover advantage. This is the reason why some US merchants put Christmas decorations on display as early as Labor Day. However, this phenomenon is limited, and we do not eventually see year-round displays of holiday merchandise.

The early display not only comes at the expense of reduced sales of other merchandise (e.g., because the shelves used for displaying the Christmas decorations cannot be used for displaying other merchandise, which in turn means 
reduced sales of the other merchandise and smaller profits for the merchants [2]) but also can face high-demand forecast errors. The previous literature shows that the uncertainty in the market demand for holiday merchandise is problematic for merchants when they have to make a decision for the display time and for the quantities of holiday merchandise to order [3-7]. A Wal-Mart survey has shown that the demand forecast error is $40 \%$ if it purchases products from suppliers 26 weeks in advance, while the forecast error is decreased to $10 \%$ if it orders products at the beginning of the sales period [8]. Hence, the forecast error is likely to be larger when the date of display is earlier. Therefore, an early display may help the merchant to capture more of the market demand but can reduce the sales of other merchandise (because the shelves are limited) and increase the sales forecast error.

This study aims to investigate the merchant's challenge of optimizing the display time and inventory management of holiday merchandise in a competitive retail market that is characterized by uncertainty, low-salvage values, and high stock-out costs. The merchant's risk preference is introduced to consider how these market strategies vary in an uncertain market environment [9-11]. In this study, a model where both the market sale and the demand forecast accuracy are time-sensitive is introduced into the decision model to numerically analyze the merchant's display time and order quantity.

The rest of this paper is organized as follows. Section 2 provides a brief literature review. Section 3 introduces the basic assumptions for the model and yields the retailer's objective function. Section 4 presents the optimal riskneutral solutions that will be used as benchmarks. Section 5 will investigate the optimal solutions for a risk-averse merchant. Section 6 gives some numerical examples and outlines the managerial implications. Section 7 concludes with a discussion of the results, and it makes some suggestions for future research.

\section{Literature Review}

Our models are largely inspired by the holiday merchandise problem and by previous studies of traditional newsvendor models that examine a demand uncertainty environment and a quick response system. In this section, we will briefly review each stream of the literature related to our study.

The first research stream of interest is demand uncertainty. The demand uncertainty of holiday products has been widely recognized as an important issue in the operations management literature. Milner and Rosenblatt tried to reduce the negative effect of uncertain demand using a quantity flexible contract [12]. Weng considered using the coordination mechanism in the supply chain to meet demand uncertainty [13]. In addition, Hua et al. considered the effects of demand uncertainty on supply chain cooperation [14]. The operational environment in this present research is similar to those presented in the previous literature [1517]. In particular, the modeling approach that is used in this study is related to the traditional newsvendor models that are used in an uncertain market demand environment.
Readers can refer to the literature [18] for an extensive review of these models. Demand uncertainty is the basic market characteristic that is faced by decision-makers. Recently, Sana and Goyal incorporated variable purchasing cost of the order quantity, lead-time-dependent partial backordering, and lost sales into the $(Q, r, L)$ model in a random demand environment [19]. Radhi and Zhang studied the optimal configuration of a remanufacturing supply network with stochastic demand [20]. Zhao et al. analyzed the lateral inventory transshipment problem for a dual-channel supply chain with uncertain market demand [21]. A substantial amount of research has assumed that uncertain demand is price sensitive, service sensitive, or both price and promised leadtime sensitive and price and service sensitive. For example, some studies have assumed that uncertain demand is both price and lead-time sensitive [11,21-24]. Xiao et al. modeled the demand uncertainty with the lead time and considered the effects of lead time and the length of selling on demand uncertainty [24]. In addition, Sana has introduced pricedependent demand with random sales price into the classical newsboy problem [25]. In summary, most of the previous studies of the newsvendor model have either assumed that uncertain market demand is independent of any decision variable or assumed that uncertain demand is price or both price and lead-time sensitive. However, both the expected market sales and the forecast accuracy in the uncertain demand environment for holiday merchandise are affected by the display time. Hence, a time-sensitive expected market and forecast accuracy demand model is introduced in this study.

The second research stream of interest is the timevariant market demand model in a quick response system. This research assumes that the merchant can enhance forecast accuracy in an uncertain market by collecting market information. For example, some literature has assumed that lead-time reduction can help enhance the forecast accuracy in an uncertain demand market [4-6, 26-28]. First, Chen and Chuang pointed out the relationships between the purchasing time and the time variance of uncertain demand and embedded the time-variant variance of demand into the classical newsvendor problem by considering the purchasing time and order quantity as a decision variable [26]. Subsequently, Chuang developed the decision model by extending the demand distribution into an unidentified demand distribution function [29]. Recently, some literature has also introduced the time-variant variance of demand model into the supply chain to consider the time factors $[5-7,30]$. For example, Wang et al. used the time-variant demand model in the supply chain to consider the retailer's purchase time and order quantity under different statement strategies [6]. Li et al. investigated the optimal lead-time policy for short life cycle products by assuming that the leadtime reduction can enhance forecast accuracy in an uncertain demand market [5]. However, replenishment lead times are much longer compared with the length of the selling season in some seasonal goods industries, which limits the merchant's opportunity to replenish the inventory during the season. Therefore, the holiday merchant must decide the order inventory by forecasting demand before the selling season. Consequently, this study assumes that not only the forecast 
accuracy but also the expected markets sales are related to the timing of displaying holiday products. The model in our study is closest to Wang et al.'s [7], who considered the display time and order quantity with the fixed purchase cost. However, as Chen and Chuang [26] pointed out, suppliers are often more than willing to carry a price discount to stimulate the merchant to purchase earlier and so decrease the inventory level. Hence, we introduce a similar time-sensitive purchase cost as that used by Chen and Chuang [26] into our model to consider the holiday merchant's marketing strategies, which differ from Wang et al.s [7].

\section{Description of the Problem}

Consider a merchant who sells a kind of holiday merchandise to the retail market, such as an artificial Christmas tree or Spring Festival merchandise. Although this holiday merchandise does not have an official start date to the market, yearround displays of this holiday merchandise do not occur in practice. Consequently, there must exist a critical time point $(t=0)$ where the potential demand may occur but the probability approximates to zero. However, delaying display after this critical point will come at the expense of less market share because it has been taken by the other merchants. Hence, we assume that the merchant will sell holiday merchandise to the market on a concentrated selling $[0, T]$ and that the market demand $D$ is random and time-sensitive with respect to the display time $t$. An early-display date can help the merchant to capture more market demand. Thus, the market demand when displaying the holiday merchandise at time $t$ can be expressed as

$$
D(t)=d-\alpha e^{-\gamma(T-t)}+\varepsilon(t), \quad 0 \leq t \leq T,
$$

where $d$ represents the maximum market demand potential and $\alpha$ represents the competitive market size (i.e., the merchant's power in the retail market). The exponential-function marketing model $e^{-\gamma(T-t)}$ is used to characterize the possible fraction of the competitive market demand that has been taken by the competitors when displaying at time $t$. The exponential-function type is widely used in the literature [31-33]. In addition, $\gamma$ is the coefficient of the elasticity of competition. The stochastic part of market $\varepsilon(t)$ is timesensitive white noise of the forecast at display time $t$ [34]. Following the model that was used by Chen and Chuang [26], we also assume $\varepsilon(t)=X(\sigma(T-t) / T), X \sim N(0,1)$, with the probability density $f(\cdot)$, and cumulative distribution function $F(\cdot)$ and its inverse function $\bar{F}(\cdot)=1-F(\cdot)$. Here, $\sigma$ represents demand deviation, that is, the market demand uncertainty. Then, we have $E(\varepsilon(t))=0, \operatorname{var}(\varepsilon(t))=\sigma^{2}(t)=(T-t)^{2} / T^{2} \sigma^{2}$. Generally, we assume that $d-\alpha \varphi(t)(>0)$ is much larger than $\sigma$ so that $\operatorname{Pr}\{D(t) \leq 0\}$ can be negligible.

Consider the following scenario faced by a merchant: $p$ represents the retail price in a competitive retail market and $s$ is the salvage price for the unsold merchandise at the end of the holiday. The supplier will charge a higher price discount $c(t)$ to stimulate the consumer to purchase earlier to allow the supplier to decrease their inventory level. Hence, it is reasonable to assume that the supplier will charge price discount $c(t)=c+\delta t$ at time $t$ to stimulate the merchant to purchase earlier, while the purchase cost must satisfy $s<$ $c(t)<p, \forall t \in[0, T]$. The holiday merchant then faces the challenge of maximizing utility by determining the order inventory and purchase time to display the product on the shelves to capture uncertain market demand, as follows:

$$
\begin{aligned}
\pi(Q, t)= & p \min (Q, D)+s[Q-D]^{+}-(c+\delta t) Q \\
& -\theta(T-t),
\end{aligned}
$$

where $\theta(T-t)$ denotes the opportunity cost because the shelves used for holiday merchandise cannot be used to display other merchandise, $[x]^{+}=\max \{x, 0\}$.

\section{The Benchmark Model}

This section will characterize the risk of the merchant's marketing strategies. Here, we first use a risk-neutral model as a benchmark. The unity for the risk-neutral merchant is the expected profit, as follows:

$$
\begin{aligned}
& E(\pi(Q, t)) \\
& =(p-s)(\mu-Q) F\left(\frac{T(Q-\mu)}{(T-t) \sigma}\right) \\
& \quad+(p-s) \sigma \frac{T-t}{T} \int_{-\infty}^{T(Q-\mu) /(T-t) \sigma} x f(x) d x \\
& \quad+(p-c-\delta t) Q-\theta(T-t),
\end{aligned}
$$

where $\mu=d-\alpha e^{\gamma(t-T)}$.

Lemma 1. For any display time $t$, a risk-neutral merchant's expected profit $E(\pi(Q, t))$ is always a concave function of the order quantity.

Proof. For any time $t$, taking the first and second partial derivatives of $E(\pi(Q, t))$ with respect to $Q$, we obtain $\partial E(\pi(Q, t)) / \partial Q=-(p-s) F(T(Q-\mu) /(T-s) \sigma)+(p-c-$ $\delta t), \partial^{2} E(\pi(Q, t)) / \partial Q^{2}=-((p-s) T /(T-t) \sigma) f(T(Q-\mu) /(T-$ $t) \sigma) \leq 0$. Hence, the expected profit is a concave function of the order quantity.

Lemma 2. For a risk-neutral merchant, the order quantity can be expressed by the purchase time as $Q_{R N}^{*}=d-\alpha e^{\gamma\left(t_{R N}^{*}-T\right)}+$ $\sigma\left(\left(T-t_{R N}^{*}\right) / T\right) F^{-1}(\beta)$, and the optimal display time $t_{R N}^{*}$ can be determined by the following algorithm:

(1) Solve the equation $\alpha e^{\gamma(t-T)}(\delta-\gamma(p-c-\delta t))-\delta d-((p-$ s) $\sigma / T)\left(F^{-1}(\beta) \beta-\int_{-\infty}^{F^{-1}(\beta)} F(x) d x\right)-((T-t) \sigma \delta / T) F^{-1}(\beta)+\theta=0$ to obtain the solutions represented as $t_{1}, t_{2}, \ldots, t_{n}$.

(2) Let $\Theta=\left\{t_{i} \mid 0 \leq t_{i} \leq T, i=1,2, \ldots, n\right\}$. 
(3) Compute the values of (3) to obtain the optimal solution as

$$
\begin{gathered}
t_{\mathrm{RN}}^{*}=\arg \max \left\{E\left(\pi\left(Q^{*}, t_{i}\right)\right), E\left(\pi\left(Q^{*}, 0\right)\right),\right. \\
\left.E\left(\pi\left(Q^{*}, T\right)\right) \mid t_{i} \in \Theta\right\},
\end{gathered}
$$

where $\beta \triangleq(p-c-\delta t) /(p-s)$.

Proof. From Lemma 1, it can be seen that the expected profit function $E(\pi(Q, t))$ is a concave function of the order quantity. Consequently, the optimal order quantity can be obtained by solving the derivatives function of $E(\pi(Q, t))$ with respect to $Q$, and then $Q_{\beta}^{*}=d-\alpha e^{\gamma(t-T)}+\sigma((T-$ $t) / T) F^{-1}(\beta), \beta \triangleq(p-c-\delta t) /(p-s)$.

By substituting $Q_{\beta}^{*}$ into formula (3), we have $E\left(\pi\left(Q_{\beta}^{*}, t\right)\right)=(p-c-\delta t)\left(d-\alpha e^{\gamma(t-T)}\right)+(p-s) \sigma((T-$ $t) / T)\left(F^{-1}(\beta) \beta-\int_{-\infty}^{F^{-1}(\beta)} F(x) d x\right)-\theta(T-t) . E\left(\pi\left(Q_{\beta}^{*}, t\right)\right)$ is a continuous and differentiable function of $t \in[0, T]$. However, it is difficult to express the analytical results because they are nonlinear. Therefore, based on algebraic theory, there exists a maximum point $t^{*}(\in[0, T])$ that satisfies $\pi\left(Q_{\beta}^{*}, t^{*}\right)=\max _{t} E\left(\pi\left(Q_{\beta}^{*}, t\right)\right)$. The optimal purchase time can then be found through the following algorithm:

(1) Differentiate the expected function $E\left(\pi\left(Q_{\beta}^{*}, t\right)\right)$ with respect to $t$ as $d E\left(\pi\left(Q^{*}, t\right)\right) / d t=\alpha e^{\gamma(t-T)}(\delta-\gamma(p-c-$ $\delta t))-\delta d-((p-s) \sigma / T)\left(F^{-1}(\beta) \beta-\int_{-\infty}^{F^{-1}(\beta)} F(x) d x\right)-((T-$ t) $\sigma \delta / T) F^{-1}(\beta)+\theta$.

(2) Let $d E\left(\pi\left(Q^{*}, t\right)\right) / d t=0$ to allow us to obtain the solutions expressed as $\left(t_{1}, t_{2}, \ldots, t_{n}\right)$.

(3) Obtain the valid extreme values set by excluding the invalid extreme as $\Theta=\left\{t_{i} \mid 0 \leq t_{i} \leq T, i=1,2, \ldots, n\right\}$.

(4) Compute the possible optimal values for the expected function $E\left(\pi\left(Q_{\beta}^{*}, t_{i}\right)\right), t_{i} \in \Theta$, and then compare these values to find the optimal time point $t_{\mathrm{RN}}^{*}$ that satisfies $t_{\mathrm{RN}}^{*}=\arg \max \left\{E\left(\pi\left(Q^{*}, t_{i}\right)\right), E\left(\pi\left(Q^{*}, 0\right)\right), E\left(\pi\left(Q^{*}, T\right)\right) \mid t_{i} \in\right.$ $\Theta\}$.

\section{The Influence of Risk Reference on a Merchant's Optimal Strategies}

The previous literature has shown that decision-makers will tend to be risk-averse because they are faced with an uncertain environment $[35,36]$. The risk-aversion issue can be addressed as the expected utility criterion [37], meanvariance objective function [38], and conditional value at risk (CVaR) [39]. In particular, the CVaR criterion measures "the average value of the profit falling below a certain quantile level; it takes into account both reward and risk," which has drawn attention in the study of operational management $[10,39,40]$. In this study, we adopt CVaR to measure the riskaverse merchant's performance.
The merchant's objective is to maximize the following utility function according to the general definition of CVaR [40]:

$$
\begin{aligned}
& \operatorname{CVaR}_{\eta}(\pi(Q, t)) \\
& \quad=\max _{v \in R}\left\{v+\frac{1}{\eta} E[\min (\pi(Q, t)-v, 0)]\right\},
\end{aligned}
$$

where $E$ is the expected operator, $R$ represents the real number set, $\eta \in(0,1]$ reflects the degree of risk aversion for the merchant (the smaller the value of $\eta$ is, the more riskaverse the retailer will be), and $v$ represents the possible upper limit of the profit under certain $\eta$.

Theorem 3. For a risk-averse merchant, the order quantity can be expressed by the purchase time as

$$
Q_{R A}^{*}=d-\alpha e^{-\gamma\left(T-t_{R A}^{*}\right)}+\frac{\left(T-t_{R A}^{*}\right) \sigma F^{-1}(\tau)}{T},
$$

and the optimal purchase time $t_{R A}^{*}$ can be determined by the following algorithm:

(1) Solve the equation $(-\delta / \eta) \sigma((T-t) / T) F^{-1}(\tau)-$ $(1 / \eta T)(p-s) \sigma \int_{-\infty}^{F^{-1}(\tau)} x d F(x)-\delta\left(d-\alpha e^{\gamma(t-T)}\right)-(p-c-$ $\delta t) \alpha \gamma e^{\gamma(t-T)}+\theta=0$ to obtain the solutions as $t_{1}, t_{2}, \ldots, t_{n}$.

(2) Let $\Gamma=\left\{t_{i} \mid 0 \leq t_{i} \leq T, i=1,2, \ldots, n\right\}$.

(3) Compute the values of formula (6) to obtain the optimal solution as

$$
\begin{aligned}
& t_{\mathrm{RA}}^{*}=\arg \max \left\{E\left(\pi\left(Q^{*}, t_{i}\right)\right), E\left(\pi\left(Q^{*}, 0\right)\right),\right. \\
& \left.E\left(\pi\left(Q^{*}, T\right)\right) \mid t_{i} \in \Gamma\right\},
\end{aligned}
$$

where $\tau \triangleq((p-c-\delta t) /(p-s)) \eta=\beta \eta$.

Proof. From the definition of CVaR, substitute $\pi(Q, t)$ into formula (5) and the optimal order quantity satisfying $Q^{*}(t)=$ $\arg \max _{\mathrm{Q} \geq 0}\left\{\max _{v} g(Q, t, v)\right\}$. Obviously, $g(Q, t, v)=v-$ $(1 / \eta) E[v-\pi(Q, t)]^{+}=v-(1 / \eta) \int_{0}^{Q}\left[v-\left(s-c_{t}\right) Q-(p-s) x+\theta(T-\right.$ $t)]^{+} d \Phi(t, x)-(1 / \eta) \int_{Q}^{+\infty}\left[v-\left(p-c_{t}\right) Q+\theta(T-t)\right]^{+} d \Phi(t, x)$, where $\Phi(t, x)$ represents the cumulative distribution function of the market demand $D(t, X)$ and $c_{t}=c+\delta t$

(1) For any given $Q, t$, we can first solve $\max _{v} g(Q, t, v)$.

Case 1. If $v<\left(s-c_{t}\right) Q-\theta(T-t)$, then $v-\left(s-c_{t}\right) Q-(p-s) x+$ $\theta(T-t)<0, v-\left(p-c_{t}\right) Q+\theta(T-t)<0$ and $g(Q, t, v)=v$, and thus $\partial g(Q, t, v) / \partial v=1>0$.

Case 2. If $\left(s-c_{t}\right) Q-\theta(T-t) \leq v \leq\left(p-c_{t}\right) Q-\theta(T-t)$, then

if $x>\left(v-\left(s-c_{t}\right) Q+\theta(T-t)\right) /(p-s)$, then $g(Q, t, v)=v$, and thus $\partial g(Q, t, v) / \partial v=1>0$; 
if $x \leq\left(v-\left(s-c_{t}\right) Q+\theta(T-t)\right) /(p-s)$, then $g(Q, t, v)=$ $v-(1 / \eta) \int_{0}^{\left(v-\left(s-c_{t}\right) Q+\theta(T-t)\right) /(p-s)} v-\left(s-c_{t}\right) Q-(p-s) x+\theta(T-$ $t) d \Phi(t, x)$, and thus $\partial g(Q, t, v) / \partial v=1-(1 / \eta) \Phi(t,(v-(s-$ $\left.\left.\left.c_{t}\right) Q+\theta(T-t)\right) /(p-s)\right)$ and $\left.(\partial g(Q, t, v) / \partial v)\right|_{v=\left(s-c_{t}\right) Q-\theta(T-t)}=$ $1-(1 / \eta) \Phi(t, 0)=1>0,\left.(\partial g(Q, t, v) / \partial v)\right|_{v=\left(p-c_{t}\right) Q-\theta(T-t)}=$ $1-(1 / \eta) \Phi(t, Q)$.

Case 3. If $v \geq\left(p-c_{t}\right) Q-\theta(T-t)$, then $g(Q, t, v)=v-$ $(1 / \eta) \int_{0}^{Q} v-\left(s-c_{t}\right) Q+(p-s) x+\theta(T-t) d \Phi(t, x)-(1 / \eta)(v-$ $\left.\left(p-c_{t}\right) Q+\theta(T-t)\right)(1-\Phi(t, Q))$, and thus $\partial g(Q, t, v) / \partial v=$ $1-(1 / \eta)(\Phi(t, Q)+1-\Phi(t, Q))=1-(1 / \eta)<0(\eta \in(0,1))$.

Combine Case 1 and Case 3; the optimal solutions for given $Q$ and $t$ must then be in the interval $\left[\left(s-c_{t}\right) Q-\theta(T-\right.$ $\left.t),\left(p-c_{t}\right) Q-\theta(T-t)\right]$.

(i) If $1-(1 / \eta) \Phi(t, Q) \leq 0$, that is, $\eta<\Phi^{-1}(t, Q)$, then the optimal solutions $\widetilde{v}$ must satisfy $1-(1 / \eta) \Phi\left(t,\left(\widetilde{v}-\left(s-c_{t}\right) Q+\right.\right.$ $\theta(T-t)) /(p-s))=0$, and thus $\widetilde{v}=\left(s-c_{t}\right) Q-\theta(T-t)+(p-$ $s) \Phi^{-1}(t, \eta)$. By substituting into $g(Q, t, v)$ in Case 2 , we have $g(Q, t, \widetilde{v})=\left(s-c_{t}\right) Q-\theta(T-t)+(1 / \eta)(p-s) \int_{0}^{\Phi^{-1}(t, \eta)} x d \Phi(t, x)$. We then have $\partial g(Q, t, \widetilde{v}) / \partial Q=\left(s-c_{t}\right)<0$. Hence, there is no extreme value for $Q$ under this situation.

(ii) If $1-(1 / \eta) \Phi(t, Q) \geq 0$, that is, $\eta \geq \Phi^{-1}(t, Q)$, then the optimal value $\widetilde{v}$ can be obtained as $\widetilde{v}=\left(p-c_{t}\right) Q-\theta(T-t)$.

(2) By substituting $\widetilde{v}$ into $g(Q, t, v)$ in Case 2, we have $g(Q, t, \widetilde{v})=\left(p-c_{t}\right) Q-\theta(T-t)-(1 /$ 7) $\int_{0}^{\left(\left(p-c_{t}\right) Q-\theta(T-t)-\left(s-c_{t}\right) Q+\theta(T-t)\right) /(t-s)}\left(p-c_{t}\right) Q-\theta(T-t)-(s-$ $\left.c_{t}\right) Q-(p-s) x+\theta(T-t) d \Phi(t, x)=\left(p-c_{t}\right) Q-\theta(T-t)-$ $(1 / \eta) \int_{0}^{Q}(p-s)(Q-x) d \Phi(t, x)$. Taking the first and second partial derivatives of $g(Q, t, \widetilde{v})$ with respect to $Q$ yields $\partial g(Q, t, \widetilde{v}) / \partial Q=\left(p-c_{t}\right)-(1 / \eta) \int_{0}^{Q}(p-s) d \Phi(t, x)=(p-$ $\left.c_{t}\right)-(1 / \eta)(p-s) \Phi(t, Q), \partial^{2} g(Q, t, \widetilde{v}) / \partial Q^{2}=-(1 / \eta)(p-$ $s) \phi(t, Q) \leq 0$. Hence, $g(Q, t, \widetilde{v})$ is the concave function of the $Q$. Thus, let $\partial g(Q, t, \widetilde{v}) / \partial Q=0$ to obtain the riskaverse merchants' optimal order quantity $Q_{\mathrm{RA}}^{*}=d-$ $\alpha e^{-\gamma(T-t)}+(T-t) \sigma F^{-1}(\tau) / T, \tau \triangleq\left(\left(p-c_{t}\right) /(p-s)\right) \eta$.

By substituting $Q_{\mathrm{RA}}^{*}$ into $g(Q, t, \widetilde{v})$, we obtain $g\left(Q_{\mathrm{RA}}^{*}, t, \widetilde{v}\right)=\left(p-c_{t}\right) Q_{\mathrm{RA}}^{*}-\theta(T-t)-(1 / \eta)(p-$ $s) Q_{\mathrm{RA}}^{*} \int_{0}^{\mathrm{Q}_{\mathrm{RA}}^{*}} d \Phi(t, x)+(1 / \eta)(p-s) \int_{0}^{\mathrm{Q}_{\mathrm{RA}}^{*}} x d \Phi(t, x)=$ $\mathrm{Q}_{\mathrm{RA}}^{*}\left(p-c_{t}-(1 / \eta)(p-s) \Phi\left(t, \mathrm{Q}_{\mathrm{RA}}^{*}\right)\right)-\theta(T-t)+(1 / \eta)(p-$ s) $\int_{0}^{\mathrm{Q}_{\mathrm{RA}}^{*}} x d \Phi(t, x)=(1 / \eta)(p-s) \int_{0}^{\mathrm{Q}_{\mathrm{RA}}^{*}} x d \Phi(t, x)-\theta(T-t)=$ $(1 / \eta)(p-s) \int_{-\infty}^{F^{-1}(\tau)} d(t, z) d F(z)-\theta(T-t)=(1 / \eta)(p-s) \sigma((T-$ $t) / T) \int_{-\infty}^{F^{-1}(\tau)} x d F(x)+(p-c)(d-\alpha \varphi(t))-\theta(T-t)$. Noticeably, $g\left(Q_{\mathrm{RA}}^{*}, t, \widetilde{v}\right)$ is a nonlinear function and is a continuous and differentiable function of $t \in[0, T]$. Hence, it is difficult to express the analytical optimal solutions. However, based on algebraic theory, there exists a maximum point $t^{*}(\in[0, T])$ which satisfies $g\left(Q_{\mathrm{RA}}^{*}, t^{*}, \widetilde{v}\right)=\max _{t} g\left(Q_{\mathrm{RA}}^{*}, t, \widetilde{v}\right)$. The optimal point $t^{*}$ can be found through the following algorithm:

(1) Take the first and second partial derivatives of $g\left(Q_{\mathrm{RA}}^{*}, t, \widetilde{v}\right)$ with respect to $t$ as $\partial g\left(Q_{\mathrm{RA}}^{*}, t, \widetilde{v}\right) / \partial t=(-1 /$ $\eta T)(p-s) \sigma \int_{-\infty}^{F^{-1}(\tau)} x d F(x)+(1 / \eta)(p-s) \sigma((T-t) /$ $T) F^{-1}(\tau)(d \tau / d t)-\delta\left(d-\alpha e^{\gamma(t-T)}\right)-(p-c-\delta t) \alpha \gamma e^{\gamma(t-T)}+$ $\theta$.
(2) Let $\partial g\left(Q_{\mathrm{RA}}^{*}, t, \widetilde{v}\right) / \partial t=0$ and then obtain the extreme points expressed as $\left(t_{1}, t_{2}, \ldots, t_{n}\right)$.

(3) Exclude the invalid extreme points and obtain the valid extreme points set as $\Gamma=\left\{t_{i} \mid 0 \leq t_{i} \leq T, i=\right.$ $1,2, \ldots, n\}$.

(4) Substitute these valid extreme points into $g\left(Q_{\mathrm{RA}}^{*}, t, \widetilde{v}\right)$ and compare these values to find the optimal time points $t_{\mathrm{RN}}^{*}$ that satisfy $t_{\mathrm{RA}}^{*}=\arg \max \left\{g\left(Q_{\mathrm{RA}}^{*}, t_{i}\right), g\left(Q_{\mathrm{RA}}^{*}, 0\right), g\left(Q_{\mathrm{RA}}^{*}, T\right) \mid\right.$ $i=1,2, \ldots, n\}$.

\section{Numerical Examples and Managerial Insights}

It is difficult to obtain the analytical solutions for nonlinear decision equations. Thus, we will conduct a numerical analysis to better understand the impact of these parameters on the risk reference of the merchants' market strategies. We will then make some recommendations for holiday merchants. Our focus is on investigating how the risk-averse merchant makes the strategies, display time, and order quantity reflect the various influential parameters. To illustrate the impacts of these important parameters, we assume that $T=120$, $d=10000, p=100, s=25, \theta=30, c=50$, and $Y \sim N(0,1)$.

6.1. The Effects of the Degree of Risk Aversion $\eta$. In the theoretical analysis, we represent the degree of risk aversion with $\eta$; that is, a smaller $\eta$ means that the merchant is more risk-averse. In particular, the merchant is risk-neutral when $\eta=1$. Figure 1 suggests that a risk-averse merchant will delay the display time and decrease the order quantity as the merchant becomes more risk-averse. Generally, when the merchant is less risk-averse, the display will be made earlier and the order quantity will be larger. In reality, a risk-averse merchant may prefer spending more time enhancing the forecast accuracy. They may then lose the potential market and they would finally have to order a smaller quantity to meet the follow-up market demand. Risk-averse merchants always lose profit due to their risk preference. Therefore, the risk-averse merchant has to weigh the time-sensitive market demand with the forecast accuracy.

6.2. The Effect of the Uncertainty of Market $\sigma$. Figure 2 presents how the market demand uncertainty influences the merchant's display time, order quantity, and profit. From Figure 2, we can see that all of the merchants would opt to delay the display time and decrease the order quantity to meet market demand. Actually, all of the merchants will choose to wait or collect information to further enhance the accuracy of their market forecast when faced with high market demand risk. In particular, the risk-averse merchant may give up the early display entirely when faced with high market demand risk. Meanwhile, the risk-averse merchant would tend to capture the fist-mover advantage when faced with clear market demand. In addition, the merchant's profit decreases as the uncertainty of market demand increases. However, the risk-neutral merchant's profit decreases sharply and will finally tend toward the risk-averse merchant's profit with large market uncertainty. A comparison of the strategies 

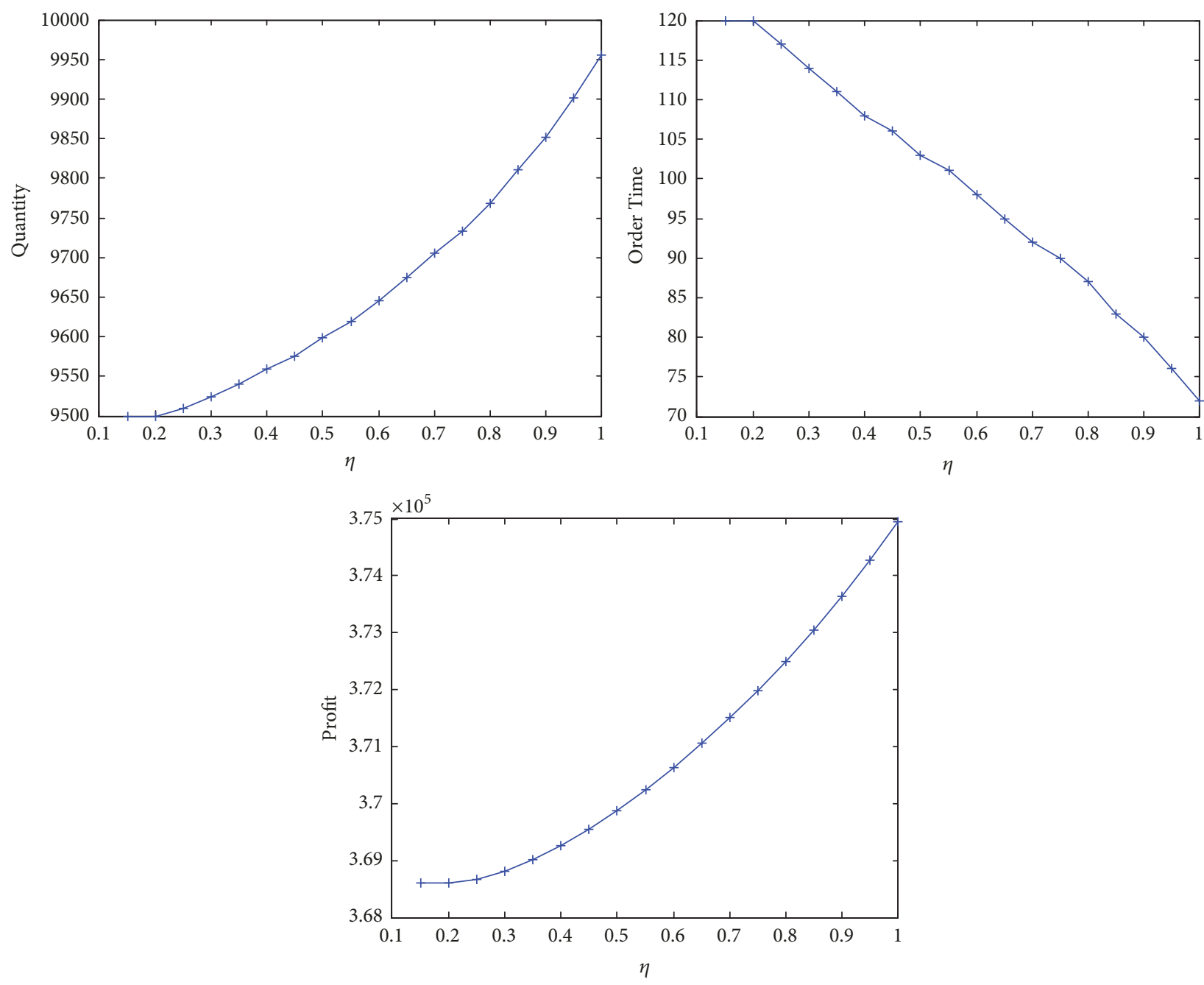

FIGURE 1: The effects of degree of risk aversion $\eta$ with $\alpha=500, \sigma=1000$, and $\gamma=0.025$.

used by these two types of merchants shows that risk-neutral merchants order more holiday merchandise to capture the early-display advantage and will capture more profit than the risk-averse merchant, even with increased market uncertainty.

6.3. The Effect of the Coefficient of Elasticity of Competitive $\gamma$. Here, $\gamma$ represents the coefficient of the elasticity of competition; that is, a larger $\gamma$ means that the market demand will make a loss due to the late display at the early stage less likely. Figure 3 shows the effects of the coefficient of the elasticity of competition on the merchant's market strategies. From Figure 3, we can see that if the market demand is less likely to be taken by competitors, then all rational merchants will choose the delay display time to decrease the opportunity cost and enhance the forecast accuracy. Meanwhile, all rational merchants will choose an early display to capture the fistmover advantage. Hence, the merchants of different risk preferences tend to display their holiday products at the same time with larger $\gamma$. Although the certainty level of risk-neutral merchant's order quantity fluctuates, the riskaverse merchant's order quantity increases with $\gamma$. This may happen because a large $\gamma$ only coincides with the risk-averse merchant's order strategies, so the risk-averse merchant's order quantity is more sensitive to $\gamma$ than that of the riskneutral merchants. Finally, the merchant's profits will benefit from high forecast accuracy and a decrease of the opportunity cost.

6.4. Effect of Purchase Discount Factor $\delta$. As described previously, the aim of the price discount provided by the supplier is to stimulate the merchant to purchase earlier. When $\delta$ is larger, the cost charged by the supplier due to the delayed purchase will be higher. All holiday merchants are sensitive to the purchase cost. Figure 4 suggests that risk preference merchants will purchase in advance with the increase of $\delta$. Consequently, the time-sensitive purchase cost can stimulate the merchant to purchase the order earlier. In particular, the risk-neutral merchant purchases their order 

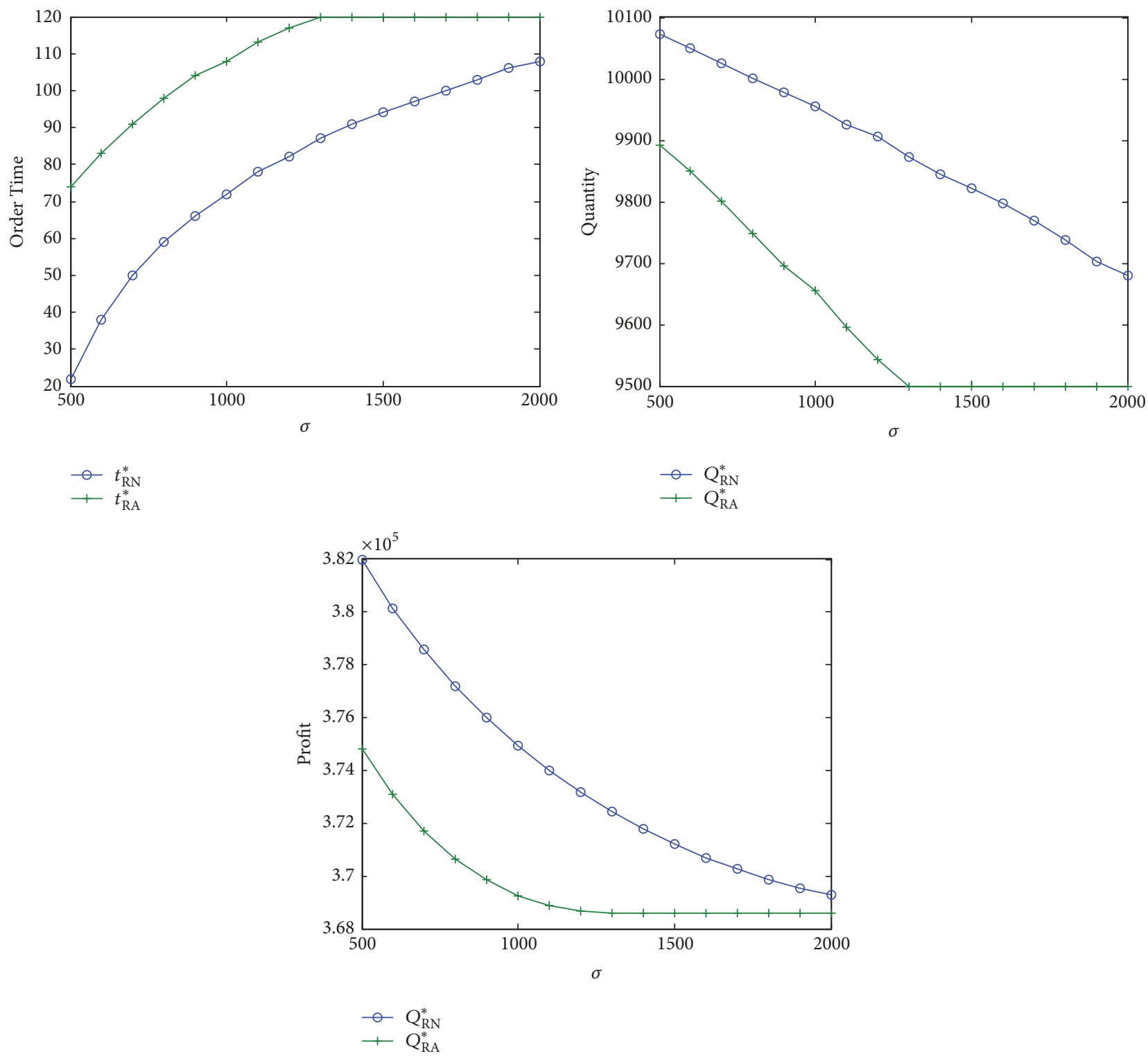

FIGURE 2: The effects of uncertainty of market demand $\sigma$ with $\alpha=500, \gamma=0.025$, and $\eta=0.8$.

in advance, even at the beginning stage. Although the riskneutral merchant's order quantity increases due to the early purchase, the risk-averse merchant's order quantity first increases due to the early purchase but it then decreases with the increase of $\delta$. This may happen because the increase of the purchase cost also means that the risk-averse merchant faces the risk of loss. Finally, the merchant's profit decreases with the increase of purchase cost. Overall, the time-sensitive purchase cost can indeed stimulate the riskaverse merchant to purchase more order in advance but this also increases their purchase cost and finally decreases their profit.

6.5. Effect of the Power of Retailer $\alpha$. The power of merchant represented by $\alpha$ indicates the degree of market demand taken by the competition. Hence, when $\alpha$ is smaller, the merchant's power will be larger and less market demand will be taken. Figure 5 illustrates the merchant's market strategies with the increase of $\alpha$. With the increase of $\alpha$, the merchant's display time will be delayed, the order quantity will increase, and finally the profit will decrease. A merchant with smaller power in the market will consider avoiding competing with a strong competitor and will then opt to display the holiday merchandise earlier to capture the firstmover advantage. A monopolist will not be afraid to lose loyal customers and will delay the display time to enhance the forecast accuracy. Therefore, a risk-neutral merchant will order a higher quantity in advance to gain the advantage. However, the risk-averse merchant's order quantity does not always increase but instead it exhibits an approximate $\mathrm{U}$ type fluctuation. The early display means that a risk-averse 

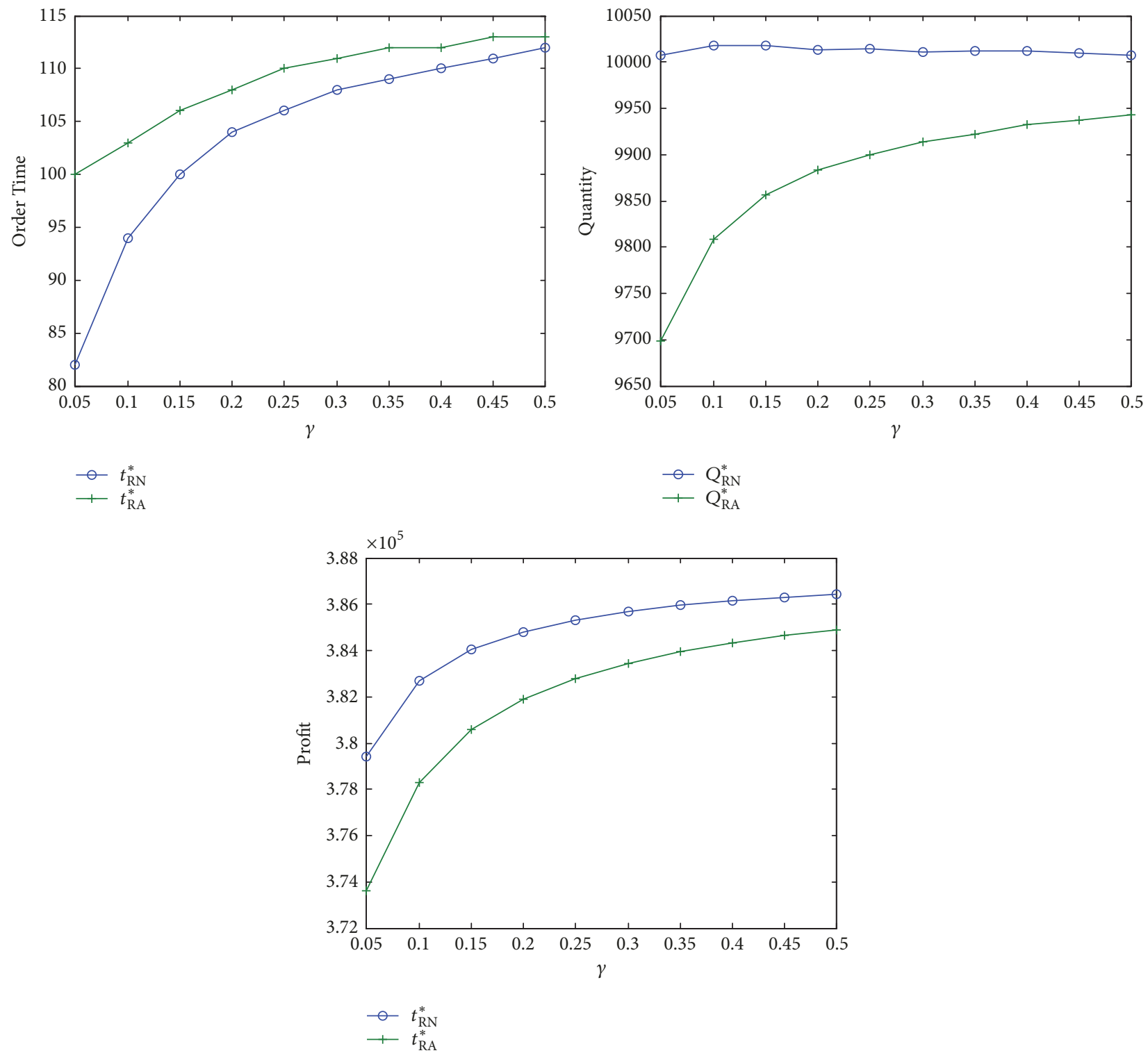

FIGURE 3: The effects of coefficient of elasticity of competitive $\gamma$ with $\alpha=500, \eta=0.4$, and $\sigma=1000$.

merchant must trade off the increased risk with the increased market power.

\section{Conclusion}

Holiday merchandise exhibits typical market characteristics due to its unofficial start date and limited life cycle. In this study, we have been able to capture the unique characteristics of holiday merchandise in the retail market by introducing the time-variant variance and time-variant expected market sales model. In particular, this study has investigated the market strategies that are used by merchants with different risk preferences to optimize the display time and inventory management of holiday merchandise in a competitive retail market. This work has enhanced the understanding of the phenomena of holiday goods, and it has provided management insight by conducting a numerical analysis. Our results suggest that the interactions of risk preference and the time-sensitive purchase cost have a significant effect on the merchant's market strategies. A risk-averse merchant will delay the holiday merchandise display time, decrease the order quantity, and finally miss the market opportunity. Meanwhile, the time-sensitive purchase cost can stimulate the merchant to purchase in advance, but this will also increase the merchant's order cost and will finally decrease the merchant's profit. The considerable uncertainty of the holiday market will cause the merchant to wait to avoid opportunity cost, and this pause allows them to enhance their forecast accuracy. A more risk-averse merchant may consider giving up the early-display advantage. All of the merchants, regardless of their risk preference, would prefer to enhance their forecast accuracy rather than capturing the 

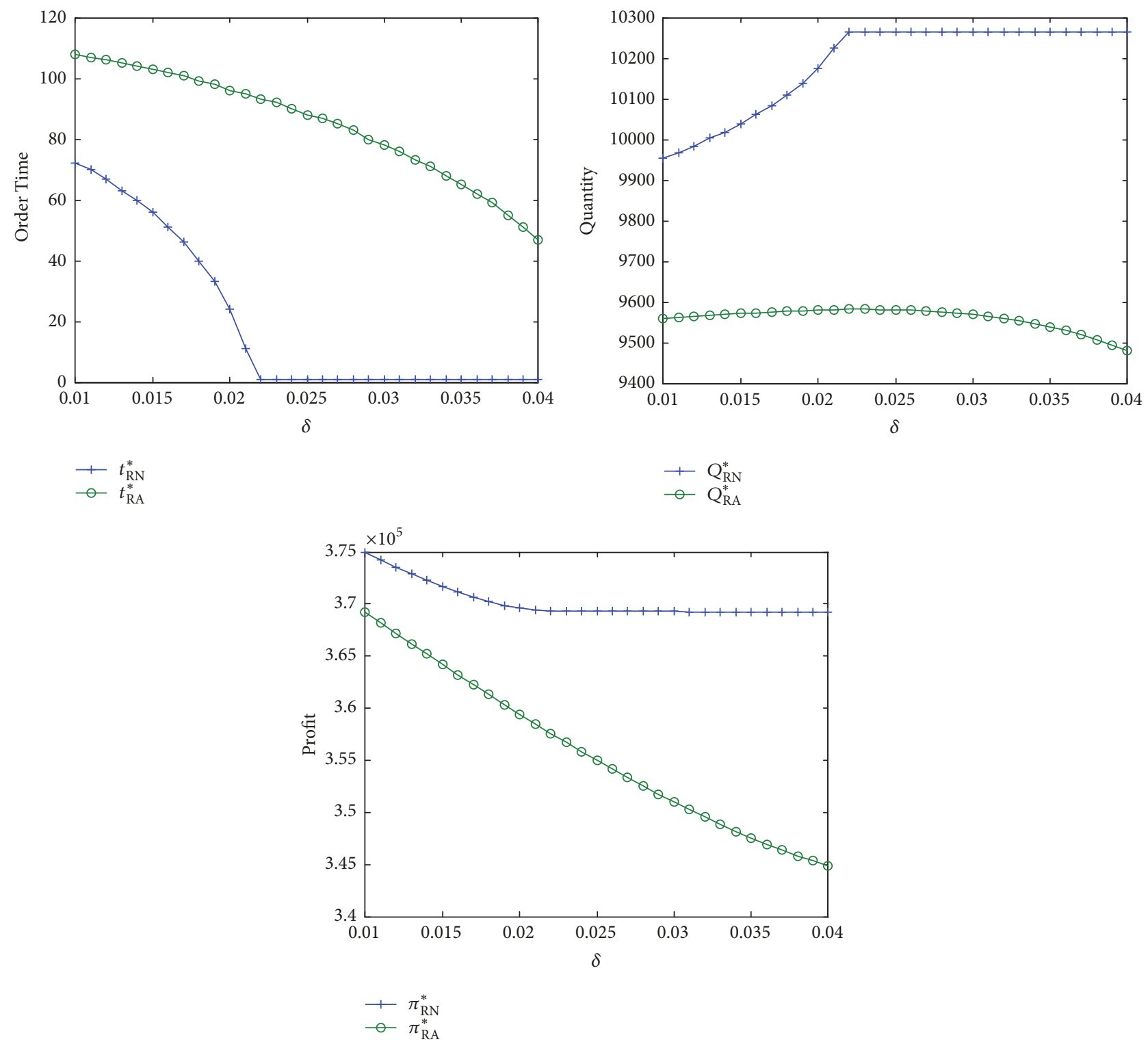

FIGURE 4: The effects of uncertainty of market demand $\sigma$ with $\alpha=500, \gamma=0.025$, and $\eta=0.4$.

early-display advantage if less of the market will be taken by the competition due to late display. A large market power merchant is not afraid to lose loyal customers due to late display. Generally, a merchant with larger market power will display their merchandise later and will make more profits. In comparison with the fixed purchase cost, a risk-averse merchant has to make a tradeoff between the challenge of making matched market strategies with the purchase cost, the advantage of early display, and the forecast error. While this study uses an extended newsvendor model, it goes further and investigates the display time and the traditional order quantity decision with time-sensitive purchase cost. This helps to offer a more detailed understanding of the interaction among these important parameters through numerical analysis.
It should be pointed out that the main limitation in the current study is that the optimal market strategies cannot be analytically derived from the decision-making equations. Therefore, we have numerically analyzed the impacts of these parameters on the risk reference merchants' market strategies. Several aspects of the present study warrant further research. For example, the scenarios that were used in this model can be extended to a supply chain context to consider the effects of the behavior of other players on the merchant's market strategies.

\section{Conflicts of Interest}

The authors declare that there are no conflicts of interest regarding the publication of this paper. 

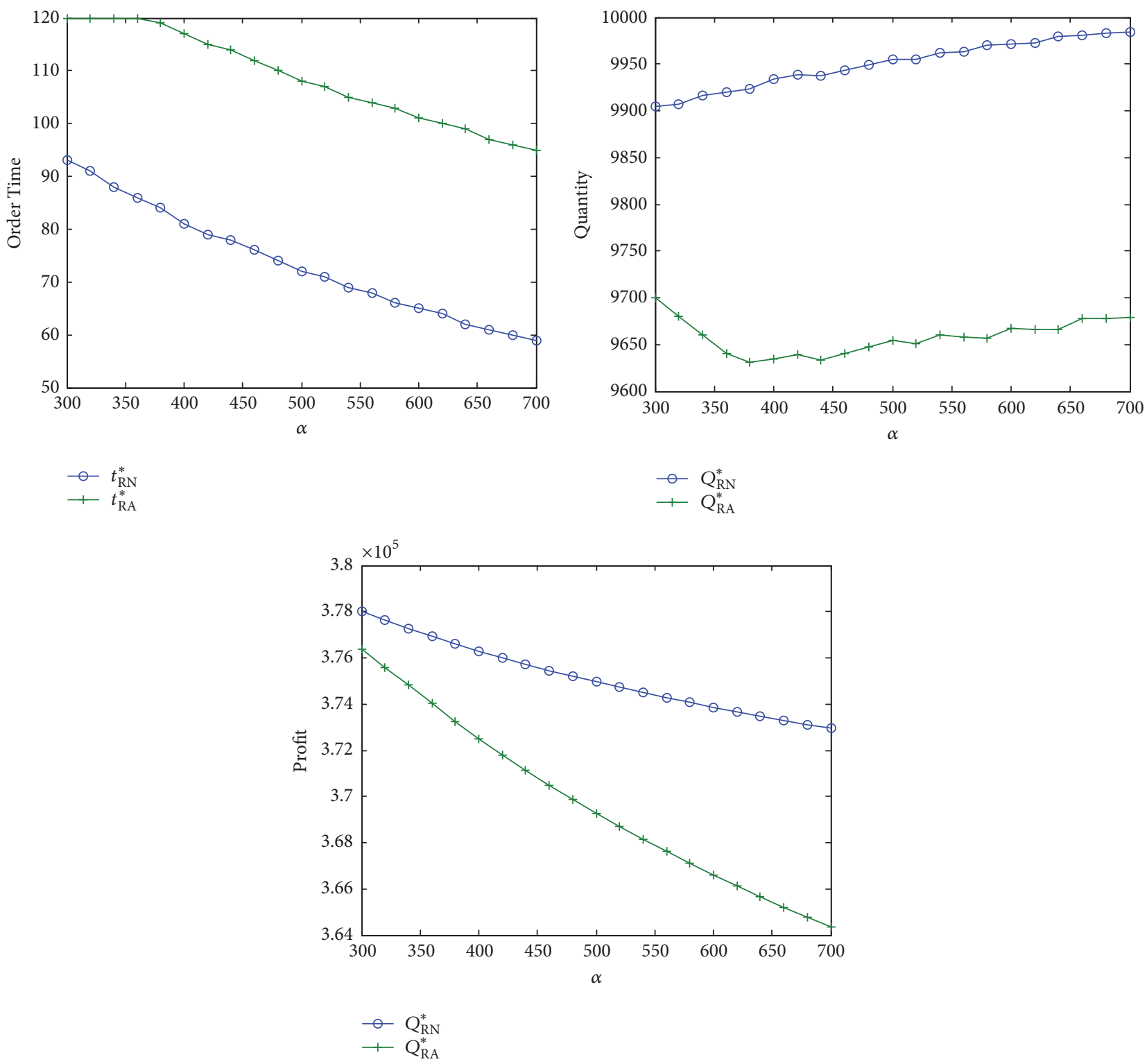

FIGURE 5: The effects of retailer's power $\alpha$ with $\sigma=1000, \gamma=0.025$, and $\eta=0.4$.

\section{Acknowledgments}

This research was supported by the National Natural Science Foundation of China (71301054), the Fundamental Research Funds for the Central Universities (2015QNXM13, 2017X2D14), Provincial Natural Science Foundation of Guangdong (2015A030310271, 2015A030313679, and 2015A030313681), and Zhongshan City Science and Technology Bureau Project (no. 2017B1015).

\section{References}

[1] G. P. Soysal and L. Krishnamurthi, "Demand dynamics in the seasonal goods industry: An empirical analysis," Marketing Science, vol. 31, no. 2, pp. 293-316, 2012.

[2] R. Frank, The Economic Naturalist: In Search of Explanations for Everyday Enigmas, Basic Book, Basic Book, 2007.
[3] M. Fisher, "What is the right supply chain for your product?" Harvard Business Review, vol. 75, no. 2, pp. 105-116, 1997.

[4] A. V. Iyer and M. E. Bergen, "Quick response in manufacturerretailer channels," Management Science, vol. 43, no. 4, pp. 559570, 1997.

[5] Y. Li, F. Ye, and Q. Lin, "Optimal lead time policy for short life cycle products under Conditional Value-at-Risk criterion," Computers \& Industrial Engineering, vol. 88, pp. 354-365, 2015.

[6] J. Wang, L. Wang, F. Ye, X. Xu, and J. Yu, “Order decision making based on different statement strategies under stochastic market demand," Journal of Systems Science and Systems Engineering, vol. 22, no. 2, pp. 171-190, 2013.

[7] J. Wang, Y. Li, F. Ye, and Q. Chen, "Optimal introduction time decision for holiday products with uncertain market demand," International Journal of Production Research, vol. 55, no. 1, pp. 161-175, 2017. 
[8] J. D. Blackburn, Time-based Competition: The Next Battleground in American Manufacturing, Irwin Professional Pub, 1991.

[9] X. Gan, S. P. Sethi, and H. Yan, "Channel coordination with a risk-neutral supplier and a downside-risk-averse retailer," Production Engineering Research and Development, vol. 14, no. 1, pp. 80-89, 2005.

[10] L. Ma, F. Liu, S. Li, and H. Yan, "Channel bargaining with riskaverse retailer," International Journal of Production Economics, vol. 139, no. 1, pp. 155-167, 2012.

[11] Y. Li, Q. Lin, and F. Ye, "Pricing and promised delivery lead time decisions with a risk-averse agent," International Journal of Production Research, vol. 52, no. 12, pp. 3518-3537, 2014.

[12] J. M. Milner and M. J. Rosenblatt, "Flexible supply contracts for short life-cycle goods: the buyer's perspective," Naval Research Logistics (NRL), vol. 49, no. 1, pp. 25-45, 2002.

[13] Z. K. Weng, "Coordinating order quantities between the manufacturer and the buyer: a generalized newsvendor model," European Journal of Operational Research, vol. 156, no. 1, pp. 148-161, 2004.

[14] Z. Hua, S. Li, and L. Liang, "Impact of demand uncertainty on supply chain cooperation of single-period products," International Journal of Production Economics, vol. 100, no. 2, pp. 268284, 2006.

[15] N. C. Petruzzi and M. Dada, "Pricing and the newsvendor problem: a review with extensions," Operations Research, vol. 47, no. 2, pp. 183-194, 1999.

[16] L. Yao, Y. F. Chen, and H. Yan, “The newsvendor problem with pricing: Extensions," International Journal of Management Science and Engineering Management, vol. 1, no. 1, pp. 3-16, 2006.

[17] Z. Wu, W. Zhu, and P. Crama, "The newsvendor problem with advertising revenue," Manufacturing and Service Operations Management, vol. 13, no. 3, pp. 281-296, 2011.

[18] T.-M. Choi and C.-H. Chiu, Risk Analysis in Stochastic Supply Chains, vol. 41, Suppl 1, International, 2012.

[19] S. S. Sana and S. K. Goyal, " $(Q, r, L)$ model for stochastic demand with lead-time dependent partial backlogging," Annals of Operations Research, vol. 233, pp. 401-410, 2015.

[20] M. Radhi and G. Zhang, "Optimal configuration of remanufacturing supply network with return quality decision," International Journal of Production Research, vol. 54, no. 5, pp. 1487$1502,2016$.

[21] F. Zhao, D. Wu, L. Liang, and A. Dolgui, "Lateral inventory transshipment problem in online-to-offline supply chain," International Journal of Production Research, vol. 54, no. 7, pp. 19511963, 2016.

[22] K. C. So and J.-S. Song, "Price, delivery time guarantees and capacity selection," European Journal of Operational Research, vol. 111, no. 1, pp. 28-49, 1998.

[23] K. Palaka, E. Erlebacher, and D. H. Kropp, "Lead-time setting, capacity utilization, and pricing decisions under lead-time dependent demand," Institute of Industrial Engineers (IIE). IIE Transactions, vol. 30, no. 2, pp. 151-163, 1998.

[24] T. Xiao, J. Jin, G. Chen, J. Shi, and M. Xie, “Ordering, wholesale pricing and lead-time decisions in a three-stage supply chain under demand uncertainty," Computers \& Industrial Engineering, vol. 59, no. 4, pp. 840-852, 2010.

[25] S. S. Sana, "Optimal contract strategies for two stage supply chain," Economic Modelling, vol. 30, no. 1, pp. 253-260, 2013.

[26] M. S. Chen and C. C. Chuang, "Extended newsboy problem with shortage-level constraints," International Journal of Production Economics, vol. 67, no. 3, pp. 269-277, 2000.
[27] G. P. Cachon and R. Swinney, “The value of fast fashion: quick response, enhanced design, and strategic consumer behavior," Management Science, vol. 57, no. 4, pp. 778-795, 2011.

[28] Y. Tamura and S. Yamada, "Reliability computing and management considering the network traffic for a cloud computing," Annals of Operations Research, vol. 244, no. 1, pp. 163-176, 2016.

[29] C.-C. Chuang, "A distribution free newsboy problem under shortage-level constraints," Journal of the Operations Research Society of Japan, vol. 44, no. 4, pp. 301-312, 2001.

[30] Y. Qin, R. Wang, A. J. Vakharia, Y. Chen, and M. M. Seref, "The newsvendor problem: review and directions for future research," European Journal of Operational Research, vol. 213, no. 2, pp. 361-374, 2011.

[31] C. B. Weinberg, G. L. Lilien, and P. Kotler, "Marketing Decision Making: A Model Building Approach," Journal of Marketing Research, vol. 21, no. 3, p. 339, 1984.

[32] K. Tang and J. Tang, "Time-based pricing and lead time policies for a build-to-order manufacturer," Production Operations Management, vol. 11, no. 3, pp. 374-392, 2010.

[33] X. Wang and D. Li, "A dynamic product quality evaluation based pricing model for perishable food supply chains," Omega, vol. 40, no. 6, pp. 906-917, 2012.

[34] C.-H. Chiu, T.-M. Choi, and D. Li, "Price wall or war: The pricing strategies for retailers," IEEE Transactions on Systems, Man, and Cybernetics: Systems, vol. 39, no. 2, pp. 331-343, 2009.

[35] Y. Deng, Y. Liu, and D. Zhou, "An improved genetic algorithm with initial population strategy for symmetric TSP," Mathematical Problems in Engineering, vol. 2015, Article ID 212794, 6 pages, 2015.

[36] Q. Qu, K.-Y. Chen, Y.-M. Wei, Y. Liu, S.-B. Tsai, and W. Dong, "Using hybrid model to evaluate performance of innovation and technology professionals in marine logistics industry," Mathematical Problems in Engineering, vol. 2015, Article ID 361275, 8 pages, 2015.

[37] L. Eeckhoudt, C. Gollier, and H. Schlesinger, "The risk-averse (and prudent) newsboy," Management Science, vol. 41, no. 5, pp. 786-794, 1995.

[38] F. Chen and A. Federgruen, "Mean-Variance Analysis of Basic Inventory Models," Financial Analyst Journal May, vol. 9, no. 3, pp. 77-88, 2000.

[39] Y. Chen, M. Xu, and Z. G. Zhang, "A risk-averse newsvendor model under the CVaR criterion," Operations Research, vol. 57, no. 4, pp. 1040-1044, 2009.

[40] L. Yang, M. Xu, G. Yu, and H. Zhang, "Supply chain coordination with CVaR criterion," Asia-Pacific Journal of Operational Research, vol. 26, no. 1, pp. 135-160, 2009. 


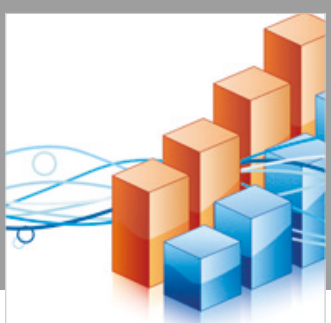

Advances in

Operations Research

\section{-n-m}
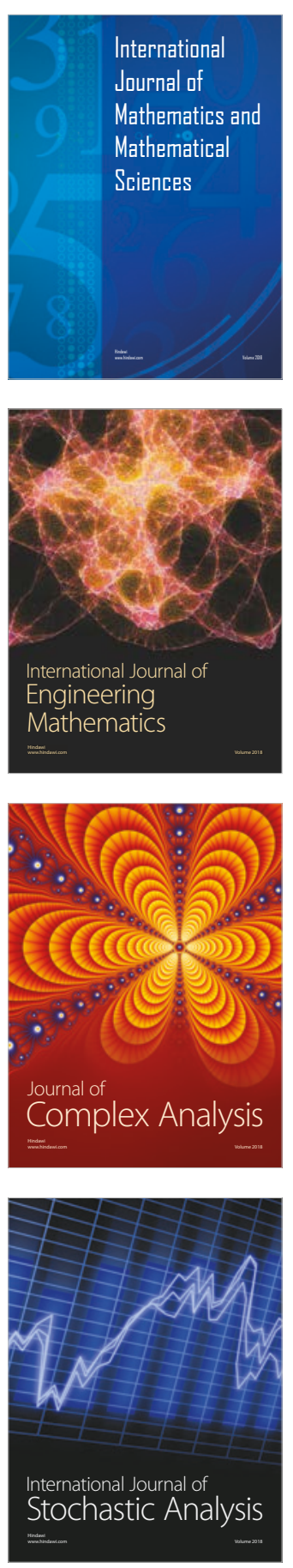
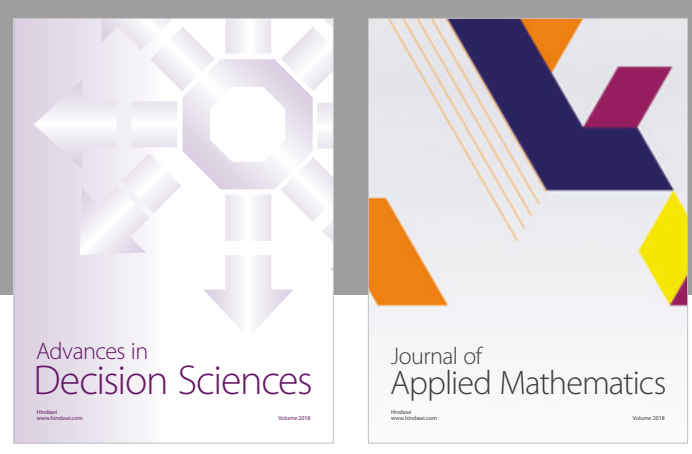

Journal of

Applied Mathematics
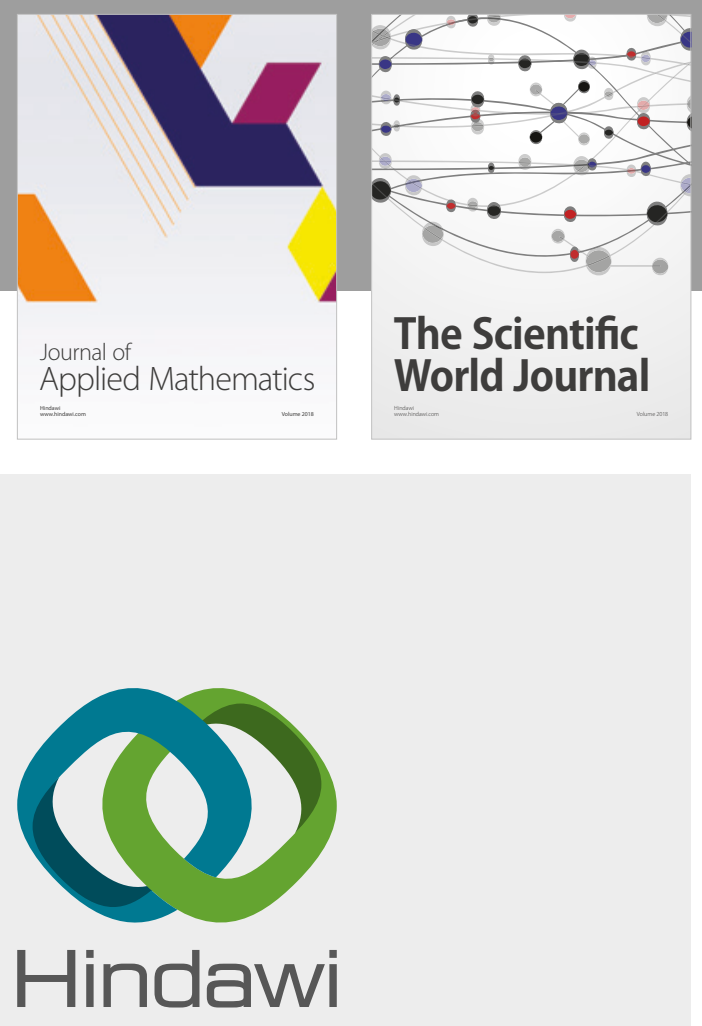

Submit your manuscripts at

www.hindawi.com

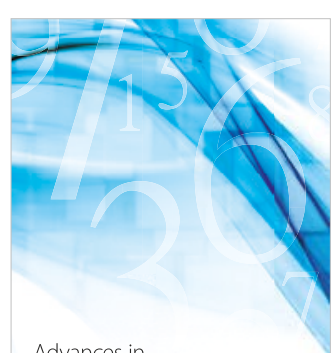

Advances in
Numerical Analysis
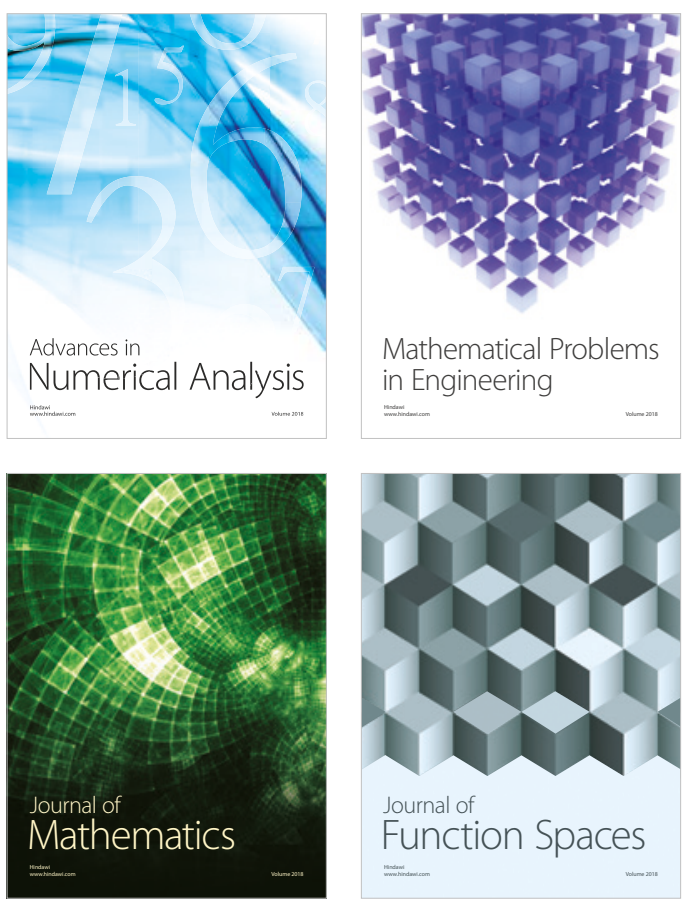

Mathematical Problems in Engineering

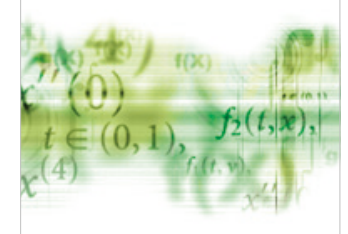

International Journal of

Differential Equations

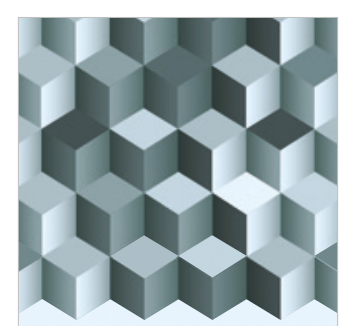

Journal of

Function Spaces

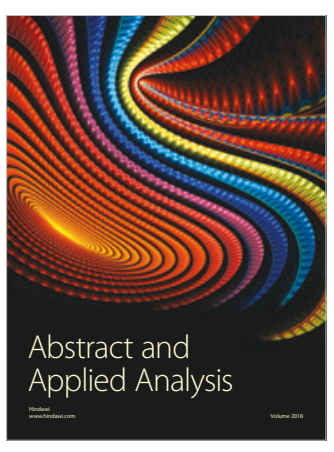

The Scientific

World Journal

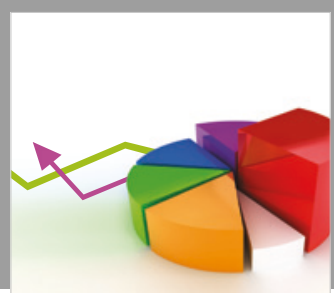

Journal of

Probability and Statistics
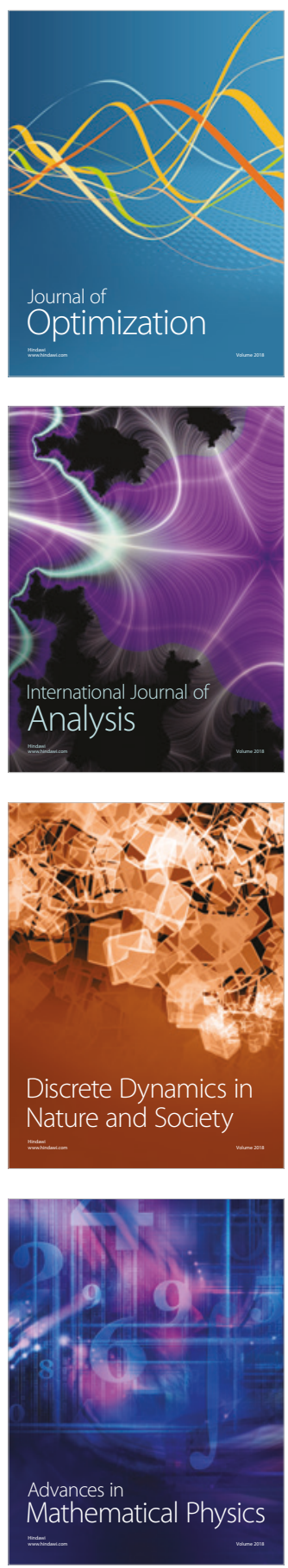